\title{
Galdós en el exilio republicano español y su recepción hispanoamericana
}

\begin{abstract}
Decía un poeta inglés, Patmore, que bay que tener muchisima fe para no creer más que en lo que vemos. Esta es la profunda fe religiosa de Galdós; y por creer tanto en lo que veía pudo realizar su temporalidad tan visible, tan claramente; tan novelescamente, es decir, tan bumana y poéticamente.
\end{abstract}

(José Bergamín, 1944: 49)

Tras la derrota en la Guerra Civil, la mayoría de la intelectualidad que había participado de los valores democráticos republicanos se vio obligada a salir del país, refugiándose principalmente en América Latina y, en particular, en México. En aquellas latitudes siguieron desempeñando su oficio de escritores, de periodistas y agitadores culturales, escribiendo en prensa y revistas, participando en homenajes y congresos o dictando clases y conferencias. En los años republicanos habían construido, como sucede con toda generación literaria, una genealogía en la que fundar su propia poética. Es sabido que el homenaje dedicado en Sevilla a Góngora -en ese momento un poeta poco reconocidoy la foto de ese encuentro, acreditaron al primero como legítimo e indiscutible antepasado literario y a los organizadores del homenaje, como miembros de la Generación del 27. En el exilio, fuera del canon de su propio país, la reflexión sobre sus orígenes literarios se hizo incluso más intensa y de esa faceta de profesores y conferenciantes resultaron publicaciones en forma de ensayos o manuales en los que confirmaban que los pilares de esa genealogía se fundaban 
en la literatura escrita en los siglos de Oro, de Cervantes a Calderón pasando por Lope o Quevedo. Y que sus referentes inmediatos eran Bécquer, Rubén Darío, Miguel de Unamuno o Juan Ramón Jiménez. En la nómina del siglo anterior, el cercano y convulso XIX, muchos de ellos citaron a un autor, Benito Pérez Galdós, pero no fue una figura tan indiscutida ni aclamada por todos ellos como fueron las anteriormente citadas. Es por esto que, en el centenario de la muerte del novelista canario, resulta interesante recuperar lo que algunos de estos poetas exiliados escribieron sobre su obra y las reflexiones que publicaron en y para un público hispanoamericano.

Galdós fue un escritor muy leído por sus contemporáneos, pero poco apreciado entre los escritores de su época y la inmediatamente posterior. Duramente criticado por Ramón Valle-Inclán, con el que mantuvo una relación difícil más allá del mítico insulto de 'garbancero' -en realidad no lo pronunció él sino su personaje, Dorio de Gadex, en Luces de Bobemia - por la 'superficialidad' con que afrontaba el análisis de la historia en sus textos; ${ }^{1}$ por Miguel de Unamuno, el caso más radical de aversión al mundo y obra galdosianos, o por Pío Baroja. También por Antonio Machado que, en el prólogo a La corte de los milagros de Valle-Inclán en 1938 afirmaba que

Don Ramón, que escribe para la posteridad y, por ende, para los jóvenes de hoy, olvida a veces, lo que nunca olvidaba Galdós: mostrar al lector el esquema histórico en el cual encuadraba las novelas un tanto frívolas de sus Episodios Nacionales. Pero don Ramón, aunque menos pedagogo, es mucho más artista que Galdós, y su obra es, además, mucho más rica de contenido histórico y social que la galdosiana. (Machado, [1938] 1983: 244)

Por el contrario, Francisco Giner de los Ríos, fundador de la Institución Libre de Enseñanza, por donde pasaron prácticamente todos los miembros de la generación del 27, tuvo un gran ascendente sobre el autor canario que, a su vez, le profesaba un gran respeto (Granados Palomares, 1993: 59). Quizá no sea casual que, por este motivo, en la generación del 27 -o en la más alargada de la República como la mayor parte de ellos gustaba llamar- la recepción galdosiana fuese menos controvertida, aunque no totalmente exenta de detractores. Quizá fuese porque el necesario parricidio literario para el relevo generacional ejecutado por los miembros de las generaciones del 98

1 Sobre este tema hay una inmensa bibliografía. Cfr. Rodríguez Padrón, 2006 y Granados Palomares, 1993. 
y 14 había allanado el camino. Atentas, amorosas y cuidadosas fueron las lecturas galdosianas de José Bergamín, Luis Cernuda y Max Aub, a pesar de mantener posturas distintas en la crítica de su literatura. Amable la de Rafael Alberti, que lo recordaba en su autobiografía cuando siendo él muy joven y recién llegado a Madrid, encontraba a un Galdós muy anciano en el parque de El Retiro posando para el escultor Victoriano Macho; cariñosa la de Federico García Lorca, agradecida la de Vicente Aleixandre y desdeñosa la de Guillén (Granados Palomares, 1993: 60).

En estas páginas se abordará lo que tres de ellos, José Bergamín, Luis Cernuda y Max Aub escribieron sobre este autor desde el exilio republicano en México. En el mapa literario que construyeron en tierras aztecas, Benito Pérez Galdós ocupó un lugar estratégico y una posición privilegiada.

En 1944, en México, José Bergamín escribe «Galdós, espejo trágico de España», el primero de varios ensayos dedicados al escritor canario. Las primeras palabras del texto son de arrepentimiento por no haber sabido, en sus años juveniles, entender la grandeza galdosiana y haberse dejado influir por el juicio de las generaciones inmediatamente posteriores al autor que lo atacaron en varios flancos, a saber: Valle-Inclán quien, a pesar de compartir con Galdós el interés por la historia como materia novelable, difería profundamente en el modo de expresarla y percibirla. Para él, inventor del grotesco esperpento, la aproximación galdosiana era demasiado pueril; Manuel Azaña, quien criticó la prolijidad galdosiana por considerarla evidente signo de imprecisión; y Ramón Gómez de la Serna que despreció la obra del autor en su totalidad.

Figuración, forma y fábula son, pues, las tres grandes críticas literarias que se le hacen en las primeras décadas del siglo XX. Y cabe añadir una cuarta, esta vez política, respecto a su anticlericalismo y su supuesta ausencia de imparcialidad. Esta crítica, Bergamín, tan convencido católico como anticlerical, la resuelve en una frase cuando afirma que «toda la novela galdosiana [responde] al principio esencial e inherente de expresar la realidad viva, reflejando las costumbres de la española que tiene delante [por lo que] la culpa no es de Galdós, sino de la sociedad española y de los católicos españoles, donde existían, en efecto, ese cura, ese obispo, ese neo, ese señor y esa señorita» (refiriéndose a los personajes de la novela Gloria) (Bergamín, [1944] 1972: 41). En cuanto a las tres críticas literarias, Bergamín se propone contrarrestarlas de la siguiente manera: defiende que Galdós forma parte de una estirpe de costumbristas entendiendo por tales a los artistas y las obras que prestan atención a las costumbres típicas de un país- que, según él, se inauguraba con el Poema del Cid y 
pasaba, por supuesto, por «Berceo, Don Juan Manuel y Juan Ruiz, Cervantes y Quevedo, Las Celestinas, Lope, don Ramón de la Cruz...» (44) para llegar sin solución de continuidad hasta Galdós, incluyendo como miembros de pleno derecho a Velázquez y Goya. Este costumbrismo para Bergamín («no hay obra literaria española, clásica ni romántica, que no pueda llamarse costumbrista») en realidad es una suerte de mímesis aristotélica profundamente influida por el pensamiento de Schopenhauer donde el autor cobra particular importancia pues «el poeta dramático o ético debe saber que él es el destino y que por ello debe ser tan inexorable como este; también debe saber que él es el espejo del género humano» (Schopenhauer, 2005: 487). Es un costumbrismo que asegura la continuidad de la literatura española.

Bergamín adopta la metáfora del espejo como instrumento en el que el poeta se mira para describir su proyección. Un espejo que a lo largo del tiempo ofrece visiones muy distintas por la variedad de cronologías que cubre y, sobre todo, por la diversidad de las miradas de los autores que se asoman a él. Pero no por esto deja de ser costumbrismo, afirma. Para limitar la discusión a los márgenes decimonónicos, considera que Larra es el primero en utilizar ese espejo trágico que le devuelve una estampa de España que lo empuja al suicidio (y no solo, afirma, por el amor de una mujer casada). La mirada de Galdós nos devuelve su novela costumbrista, una novela que es distinta a cualquier otra del mismo periodo no por ser mejor o peor que las demás, sino por su propia naturaleza. Usando como ejemplo Fortunata y Jacinta, por ser la más prolija, leída y conocida del autor, recupera la crítica de las generaciones anteriores para rebatirla: frente a la crítica de imprecisión por exceso de profusión de Manuel Azaña, Bergamín sostiene que jamás con tan 'pocas' palabras se dijeron tantas cosas. «La forma de Galdós es la precisión y concisión personificadas» (Bergamín, [1944] 1972: 47).

En la genealogía costumbrista española elaborada por Bergamín, Goya aparece como el legítimo abuelo de Galdós para afirmar que «el tiempo también pinta [...] o escribe novelas» (Bergamín, [1944] 1972: 47). Y en la novela galdosiana

el tiempo es el personaje principal [...] y es en esa [la novela galdosiana], su razón de ser temporalidad aparente o visible (que eso es, en definitiva, lo que quiere decir costumbrismo) en lo que Galdós fundamenta la esencia de la novelería, su propia sustancia imaginativa: el alma y la vida de la novela. El costumbrismo novelesco de Galdós no es otra cosa que la materialización visible del tiempo. (Bergamín, [1944] 1972: 47) 
Afirma Bergamín que «el hombre empieza a ser hombre, es decir a tener conciencia de serlo cuando se viste», refiriéndose claramente a la expulsión bíblica de Adán y Eva del paraíso terrenal, con la conciencia del pecado original y la vergüenza de la desnudez, «y por vestirse, se pone, por primera vez el hábito de la tragedia». Así, según Bergamín nace la novelería, el costumbrismo entendido como el «hábito de la temporalidad fugitiva», como el «cumplimiento mortal de un destino: la cosa trágica» pues «la costumbre es el hábito de las tragedias de los pueblos».

Nietzsche, del que Bergamín fue ávido lector, escribió en la Segunda intempestiva que el animal vive de manera ahistórica. Pero el hombre se convierte en hombre cuando comprende la palabra 'fue' con la que entiende que su existencia es un tiempo imperfecto, nunca consumado (Nietzsche, [1874] 2003: 41). Por eso solo a través de la capacidad de utilizar el pasado para poder vivir, y de hacer de lo ocurrido historia, el hombre se convierte en hombre. ${ }^{2}$ Ahora bien, hacer historia, dice el filósofo, no consiste en la simple acumulación de datos (el historicismo de su tiempo que tanto critica) pues esto no permite ir al fondo de la cuestión histórica, por una parte, porque es tan imposible recordar todo como olvidarlo. Por otra, porque esta imposibilidad obliga a elegir determinados datos en detrimento de otros, lo que destruye la supuesta objetividad científica del historicismo. De aquí que el filósofo considere necesario abordar la historia de manera trágica, sabedora de no poder construirse por la imposibilidad de priorizar entre cada uno de los hechos históricos individuales y obligada, pues, a narrarlos.

Aunque Bergamín la sustenta en el Génesis, coincide con la teoría nietzscheana en la existencia de dos entidades: una invisible -la conciencia humana o destino trágico-, y otra visible -la temporalidad pasajera, simples hechos históricos para el alemán, costumbrismo para el español-. Por eso en una novela de Galdós «todos los acontecimientos, toda la figuración fabulosa que actúa en un periodo de tiempo determinado, se verifica, por esa temporalidad visualizada plásticamente, en el mundo aparente de lo que se ve» (Bergamín, [1944] 1972: 49). De aquí que para Bergamín en las novelas de Galdós no haya exceso de fabulación ni de figuración. Ni prolijidad o profusión en la forma, «porque ese tiempo vestido, esa tragedia aparente, cotidiana y sencilla, se va

2 «es verdad que el hombre solo llega a ser hombre en tanto que pensando, reflexionando, comparando, separando y sintetizando limita ese elemento ahistórico, [...] es decir, mediante esa fuerza de utilizar el pasado como instrumento para la vida, transformando lo acontecido en Historia nueva. Pero no es menos cierto que, por medio del exceso hsitórico, el hombre deja, por el contrario, de serlo» (Nietzsche, [1874] 2003: 46). 
desarrollando con ímpetu, con esa máxima velocidad trágica del tiempo humano». Y es aquí donde reside la gran diferencia de la novela galdosiana que la convierte en magistral porque la forma, la figuración y la fabulación se entretejen con aparente superficialidad. En la novela galdosiana no hay psicología, hay alma: «el enigma del ser humano nos sale al paso, a cada paso, en las figuraciones novelescas de Galdós [...] pero con otro estilo, diría, de visión de plasticidad imaginativa más intensa, más luminosa» (Bergamín, [1959-1963] 1972: 71) Es la identificación y el reflejo de la conciencia humana y el mundo. Porque, dice Bergamín, cuando Cervantes y Dostoievski se asoman al espejo lo que hay detrás es Dios. La base especular de sus novelas está llena de Dios. La tragedia se produce cuando no hay nada. En las novelas galdosianas, en cambio, no hay dios. ¿Qué hay, pues, detrás del espejo? El pueblo español. De hecho, puntualiza Bergamín, Galdós afirmaba «no soy yo, es mi público (su pueblo) el que escribe mis novelas» (Galdós, 1897).

José Bergamín intuye tempranamente la tendencia a la dramatización de la novela de Benito Pérez Galdós, rasgo que comparte claramente con Miguel de Cervantes:

Cuando Galdós casa, poéticamente, a la novela con el drama teatral [...] intuye con certera verificación poética la gran verdad que hizo de toda obra novelesca, explícitamente, un drama teatral y de todo drama teatral, implícitamente, una novela. Novela y Teatro, decimos, que son mundos de apariencia vana: pero no engañadora. Todo lo contrario: desengañados.

La novela, pensamos y dijimos otras veces, nace del desengaño: como la poesía de la desesperación. (Bergamín, [1959-1963] 1972: 64)

A pesar de su pasión teatral ninguno de los dos alcanzó gran éxito con su dramaturgia, pero adoptaron algunas de las técnicas teatrales en sus novelas. En el caso galdosiano los diálogos y la independencia de sus personajes, que al rebajar la omnisciencia canónica del autor le permitieron jugar con distintas voces y modos de pensar y mantener una perspectiva sin precedentes en las letras españolas (Rodríguez Padrón, 2006: 16) pues sus personajes «no son abstractas generalizaciones de un tipo sino seres vivos de verdad; y que, al serlo, aciertan a veces, otras se equivocan, en su pensamiento y conducta; pero sin expresar una idea o pensamiento o sentimiento que el novelista haya tratado de imponerles» (Bergamín, [1959-1963] 1972: 74). 
Los escritores del 98 erraron los tiros, consideraron que el afán de Galdós por someterse sin concesiones a las reglas del realismo literario le había llevado a la exasperación de utilizar el lenguaje vulgar y coloquial en un medio donde no tenía cabida. En realidad, Galdós recuperó el lenguaje popular con toda su poesía, viveza y musicalidad (Millares, 2020), lenguaje que, concluye Bergamín, supone una subversión a las convenciones literarias y es, precisamente, en esta subversión galdosiana donde radica su genio. En la novela galdosiana hay una pluralidad de voces que obligan al autor a multiplicar sus lenguajes y consecuentemente la forma de la novela, para personalizarlos e independizarlos. Porque

aquellos seres galdosianos en pugna con el medio social en que viven y en lucha de ideas y sentimientos contradictorios que les prestan su realidad viva para nosotros, son, y no solamente nos lo parecen, independientes de la voluntad de su autor desde el instante en que adquieren a nuestros ojos existencia propia. No se trata de ningún pirandellismo unamuniano que les fija una voluntad contraria, opuesta a la del autor con quien dialogan de ese modo para independizarse. Eso no pasa de un divertido truco que no sale de la cabeza del autor, quien dialoga con sus fantasmas. La realidad novelesca es otra. Y la existencia personal del personaje de novela rompe, desde que nace a la imaginación, todo vínculo con su creador imaginativo. El autor puede sorprenderse de aquellos seres a que su lenguaje ha dado vida, pero no puede dialogar con ellos una vez creados si no es al modo del lector que los recrea. El autor puede recrease en su obra como un lector cualquiera pero no descrearla una vez creada. (Bergamín, [1959-1953] 1972: 72-73)

Repite incansablemente Bergamín que Galdós aclaraba siempre que no era él quien escribía sus novelas, sino sus lectores y que ahí residía la clave del error de interpretación de su obra por parte de la crítica literaria: «el vulgarismo que le atribuimos a su estilo es, en realidad, su realidad imaginativa misma; su ilusión de vida real que nos da a leer con sus ojos y sus oídos como recordábamos que decía Quevedo. Y esa ilusión de vida se nos teatraliza por lo novelesco del mismo modo que lo teatral se nos vuelve novelería» (Bergamín [1975] 198384: 196-197).

En todas las novelas galdosianas el lector es un cómplice del narrador, está al corriente de los acontecimientos, se interesa por lo que ocurre y va formando 
juicio sobre lo que acontece y sobre las consecuencias de las acciones de los personajes. A su vez, en algunas ocasiones es el narrador galdosiano el que aclara la razón por la que se menciona tal o cual detalle que no sería imprescindible para la buena marcha de la narración. Sea como fuere, es el lector el que debe integrar los diversos elementos de la novela y darle sentido. Los narradores dialogan con él, solicitan su aprobación o censura, por encima del hombro de los personajes. Se establece una curiosa asociación entre el novelista y el lector que, a medida que avanza en la lectura, sustituye al novelista, ocupa su lugar pues tiene que ir rellenando los huecos, los tiempos muertos -que en realidad no son tales-. Es el lector el que suple lo que no se dice, influido por lo que el narrador ha contado. «Los huecos son prefabricados y el lector los llena, pero recordando lo dicho por los narradores» (Germán Gullón, 1970: 78). Será el lector el que, atando los cabos que el novelista le proporciona, concluya o redondee la novela.

Max Aub, parisino de nacimiento, español por elección, tras la guerra civil pasó por varios campos de concentración y acabó exiliado en México, donde se dedicó a una febril actividad intelectual. En 1945 dictó un «Discurso sobre la novela contemporánea», apuntes que en 1966 publicó en el Manual de bistoria de la literatura española. En esas páginas, al igual que había hecho antes Bergamín, convirtió en parabienes las críticas que el escritor canario había recibido de las generaciones pretéritas. Donde estos vieron defecto en forma, fábula y figuración, Aub escribió que «desde Lope ningún escritor fue tan popular; ninguno tan universal desde Cervantes».

No es casual la atención que Aub fija en Galdós pues también a él le interesa la dramatización del hecho histórico. Desde la ficción narra la cotidianeidad de individuos comunes que pertenecen a su siglo, en este caso el $\mathrm{XX}$, como Galdós había hecho para el XIX. Y lo hace con la intención de dotar al pasado de significado (interés que comparten, como demuestra el ciclo de novelas de Aub sobre la guerra civil española, El laberinto mágico). Con ese afán pedagógico por novelar el mundo y convertirlo en libro abierto para la sociedad. Por eso, lo más destacable de la obra galdosiana, en opinión de Aub, es que el novelista canario ha hecho más por el conocimiento de España, de sus habitantes y sus geografías que todos los historiadores juntos pues:

Perdiérase todo el material histórico de esos años, salvándose la obra de Galdós, no importaría. Ahí está completa, viva, real, la vida de la nación durante los cien años que abarcó la garra del autor. Existen, para siempre, sus centenares y centenares 
de personajes históricos e imaginados, tan ciertos los unos como los otros. (Aub [1966] 1974: 450)

A propósito de la técnica galdosiana, Aub apuntaba que solía ser dramática o melodramática ceñida a los dos modelos tradicionales: en el que se presentaba el problema y se solucionaba a lo largo de la fábula o en el que se preparaba la sorpresa. Fuera uno u otro, Galdós siempre conseguía mantener despierto el interés del lector que no sospechaba los desenlaces a costa de, en ocasiones, forzar la verosimilitud. A propósito de la prosa, en cambio, sostenía que

No es brillante, ni afiligranada, su estilo pierde la rigidez académica, el reubicamiento arcaizante para lograr el castizo contraste diario con el pueblo. [...] Un estilo vulgar, una manera de escribir al alcance de los más: el estilo sobrio, claro y neto de los grandes novelistas del siglo XIX. Un estilo objetivo. Un estilo liberal, directo, preciso, arrastrado por los sucesos que, cuando aúna el temblor del propio sentimiento a lo que describe, da en aciertos impares. Una manera de dibujar y pintar tan varia y viva que, cuando rompen a hablar sus miles de personajes [...] nunca se confunden y cada cual se presenta en los dinteles del recuerdo con su indumentaria propia y sus pensamientos correspondientes. (Aub [1966] 1974: 447)

Luis Cernuda, exiliado en México, dedicó un ensayo muy personal en 1954 a Galdós en el que resaltaba la figura del escritor pues encontraba muchos puntos de conexión en la vida de ambos. El texto de 1954 es «una especie de manifiesto del escritor que se sabe contrario a las corrientes oficiales de la literatura» (Rosell, 2008: 3). Galdós había sido vapuleado por la generación del 98 y por la posterior del 14. Aunque fue un escritor muy leído en su tiempo, la crítica literaria lo despreció y ninguneó sistemáticamente. Y Cernuda concluyó que

no podemos dudar de que Galdós fuera en su tiempo un autor leído, ni de que lo siga siendo hoy; el número de sus ediciones lo comprueba. Ahora, que fuera o que sea un autor comprendido, en su tiempo o en el nuestro, es otra cuestión. Baste con indicar cómo entonces y ahora se le solía y se le suele comparar, a él, no solo con Varela, sino con Pereda. Se diría que aún no han nacido sus lectores verdaderos, y puesto que va transcurrido largo espacio de tiempo desde la composición y publicación 
de sus obras, durante la mitad segunda del siglo pasado, y de su muerte, hace más de treinta años, sin que dichos lectores aparecieran, pudiera añadirse, tal vez sin riesgo grave de equivocarse, que hay poca probabilidad de que aparezcan nunca. (Cernuda, [1954] 1994: 517)

Es evidente que en esta afirmación había mucho de personal porque también Cernuda se sentía, más aún en el exilio, abandonado y excluido. Sostuvo que la honestidad y discreción galdosiana «le impidió utilizar su obra para hablar de sí y hacer en ella su propio reclamo, como lo han hecho hasta la náusea las gentes del 98» (Cernuda, [1954] 1994: 517).

Como ya había hecho Bergamín, Cernuda desmonta la crítica galdosiana de las generaciones posteriores pues no considera que la prolijidad de su obra sea un problema, al contrario «entiéndase que la cantidad de obra en Galdós no supone, como en Lope o en cualquiera de nuestros dramaturgos torrenciales, una dilución del poder creador a expensas del aquilatamiento. Todo lo que Galdós escribió, cuenta» (Cernuda, [1954] 1994: 518). Como tampoco lo es su escritura pues

Se ha repetido que Galdós no sabe escribir, que no tiene 'estilo'. No sé qué llamarán estilo quienes tal cosa dicen. Galdós creo para sus personajes un lenguaje que no tiene precedentes en nuestra literatura, ni parece que nadie haya intentado continuarlo o podido continuarlo. Cada personaje de sus novelas nos habla por sí mismo; es un lenguaje directo y revelador, familiar y sutil a un tiempo. (Cernuda, 1994: 518)

También Cernuda se une a las críticas de Galdós como dramaturgo, pero resalta que de aquel instinto dramático surgió el uso del diálogo y del monólogo en sus novelas, dejando que sus personajes hablaran por sí mismos, que se independizaran de su autor. «Así inventa una lengua 'dramática' que anticipa lo que años después se llamaría 'monólogo interior'» (Cernuda, [1954] 1994: 521).

En definitiva, para todos estos autores Galdós se presenta como un visionario, como el 'escritor de su siglo', como el novelista que mejor sabe sacar a la luz las miserias y las bondades de su tiempo, sus luces y sus sombras. Para Bergamín sobre todo porque en sus novelas hay alma (figuración). Para Cernuda porque su escritura es tan brillante que todavía no han nacido sus lectores (forma). Para Aub porque aunque borrasen la historia de todo el siglo no importaría, porque queda su obra (fábula). En definitiva, los tres pilares de la obra del 
autor canario son devotamente defendidos de las duras críticas que el canario recibió de los escritores de las generaciones del 98 y 14.

Los elogios de estos tres intelectuales republicanos en el exilio mexicano tienen un eco en la definición de contemporáneo del filósofo italiano Giorgio Agamben: «il poeta - il contemporaneo- è colui che tiene fisso lo sguardo nel suo tempo, per percepirne non le luci ma il buio. Tutti i tempi sono, per chi ne esperisce la contemporaneità, oscuri. Contemporaneo è, appunto, colui che sa vedere questa oscurità, che è in grado di scrivere intingendo la penna ne1la tenebra del presente» (2008: 13). Por este motivo concluyen estas páginas con una reflexión de Carlos Blanco Aguinaga ${ }^{3}$, crítico literario que durante sus años de juventud y formación estuvo en contacto con la intelectualidad republicana exiliada en México adonde llegó él también exiliado, pero aún niño. Además de considerar muy acertada su reflexión la recupero en este texto porque me parece el mejor ejemplo de la recepción hispanoamericana de un autor a través de la sensibilidad literaria de los exiliados republicanos y de una intelectualidad mexicana afín a considerar la literatura en lengua española en claves diferentes a las territoriales o nacionales. $\mathrm{Y}$ es, precisamente, el que mejor desentraña las luces y las sombras que nos propone Galdós cuando nos advierte que «no debe el lector cometer el error que el autor no comete cuando nos lleva a interesarnos por un personaje que, de por sí (si «existiera»: fuera de la novela), podría no ser en nada interesante» pues «el que un personaje carezca de cualidades extraordinarias y le ocurran cosas vulgares, no significa en absoluto que no aparezca viviendo con la complejidad suficiente para atraer al lector hacia su problemática» (Blanco Aguinaga, 1978: 21). Aguinaga, desde su materialismo histórico, nos advierte de que a Galdós hay que leerlo como lo que es. Su sustrato es la historia misma, la historia de lo que él llama el 'mestizaje oligárquico' que no es sino la categoría que otorga para denominar el avance inexorable de la burguesía en detrimento de la aristocracia oligárquica. A sus personajes hay que leerlos por lo que son. En el caso concreto de Máximo Manso (El amigo Manso), que ejemplifica, un insignificante pequeño burgués. Pero en la obra galdosiana en conjunto -que, decía Torres Bodet que

3 Nacido en España, con 10 años salió junto a su familia al exilio en México donde estudio en el Colegio Luis Vives en el que enseñaban una buena parte de los intelectuales y donde entabló una fuerte amistad con los hijos de otros exiliados republicanos, los llamados «exiliados de segunda generación». Después estudió en Harvard y se doctoró en el Colegio de México con Alfonso Reyes (quien, en 1943, en México, había escrito unas letras sobre Galdós. $C f r$. Reyes 1957). Se dedicó a la crítica y la enseñanza de la literatura en lengua española en varias universidades americanas. Durante los últimos años fue, además, catedrático extraordinario en la Universidad del País Vasco. 
es como hay que valorar a Benito Pérez Galdós (1969: 170) - es la bisagra que ha de permitir a un pequeño burgués (el hijo de un carnicero) arribar a las esferas del poder.

El interés galdosiano por las relaciones dialécticas entre literatura e historia es evidente y la técnica literaria esgrimida para remitir a los hechos históricos es la alusión indirecta por dos procedimientos contrarios: la simple mención de la fecha en la que están ocurriendo ciertos hechos -sin que se especifique por qué esa fecha es importante fuera de la ficción- o la referencia a hechos sin años o años sin hechos concretos. Pero

hasta tal grado es avasalladora la personalidad de los personajes (y no solo de Fortunata), tal es el arte de novelar de Galdós, que, si acaso, lo que ocurre es lo contrario, no siendo extraño, por lo tanto, que las mejores lecturas críticas de la novela, sin pasar en absoluto por alto las relaciones que el narrador establece entre Fortunata y «pueblo», subrayen precisamente la especificidad de los personajes y sus peripecias. (Blanco Aguinaga, 1978: 56)

En suma, de la misma manera que un grupo de poetas amigos, en 1927, en una fiesta sin más pretensiones que disfrutar de la poesía de un autor olvidado como Góngora, convirtieron el homenaje en una restitución del autor a una genealogía literaria, el exilio republicano -Bergamín o Cernuda participan en ambos 'homenajes'- devolvió a Galdós a la centralidad que de pleno derecho le correspondía en dicha genealogía. Porque como defiende Burger

Tenemos un pasado, pero nos damos una Historia. Y nos la damos a la luz de un diseño - un diseño de lo que somos y lo que queremos ser: de ello depende lo que hemos sido. No es el pasado lo que nos determina y define, sino que, en tanto le conferimos al pasado que tenemos una estructura significante... y a través de ella lo convertimos en nuestra historia, en nuestro 'haber-sido' [...] nos definimos a nosotros mismos mediante nuestra propia historia. (Burger 2007: 36$)^{4}$

Concluye Bergamín sugiriendo un paralelismo entre la España fratricida que fue durante el siglo XIX, reflejada por Galdós y Goya y la que se repitió en los

4 Cfr. Burger, R. (2007). Im Namen der Gescbicbte: Vom Mißbrauch der bistoriscben Vernunft. Zu Klampen. Trad. de Lucía Luna Elek en Herbert Frey. 
inicios del XX (1979b: 172). Porque «es ese mismo espejo que nos explica una España pasada el que [...] justifica una España futura» ([1944] 1972: 55). De hecho, en esa metáfora del espejo, la tragedia contemporánea española que él creyó ver reflejada fue la del exilio republicano.

\section{Bibliografía}

Agamben, G. (20175): Cos'è il contemporaneo. Milano: Nottetempo.

Aub, M. (1945): «Discurso De La Novela Española Contemporánea». Jornadas, 50, Colegio De México: www.jstor.org/stable/j.ctv8bt2w5.

Aub, M. ([1966] 1974): Manual de bistoria de la literatura española. Madrid: Akal.

Bergamín, J. ([1944] 1972): «Galdós, espejo trágico de España: hablar de Galdós». En: De una España Peregrina. Madrid: A1-Borak, 33-56.

Bergamín, J. ([1959-1963] 1972): «Galdós, espejo trágico de España: el pensamiento religioso de Galdós». En: De una España Peregrina. Madrid: AlBorak, 56-76.

Bergamín, J. ([1975] 1983-84): «Galdós visionario». Sábado Gráfico, 930, 29 marzo 1975, 21. Compilado en «José Bergamín: el pensamiento de un esqueleto. Antología periodística». Revista Litoral, 1, 193-197.

Bergamín, J. (1979): «Tolstói y Galdós». En: Calderón y cierra España. Madrid: Planeta, 156-166. Reedición de La corteza de la letra. Buenos Aires: Losada, 1957.

Bergamín, J. (1979b): «Galdós y Goya». En: Calderón y cierra España. Madrid: Planeta, 167-172. Reedición de La corteza de la letra. Buenos Aires: Losada, 1957.

Blanco Aguinaga, C. (1978): La bistoria y el texto literario. 3 novelas de Galdós. Madrid: Editorial Nuestra Cultura.

Cernuda, L. ([1954] 1994): «Galdós». En: Prosa I. Madrid: Siruela. Vol. 2, 517-524.

Frey, H. (2015): «Nietzsche: la memoria, la historia: la Segunda intempestiva entre la crítica al historicismo y la negación de la filosofía de la historia». Cuicuilco, 64, 271-290.

Granados Palomares, V. (1993): «Galdós entre el 27». En: Jesús Bombín Quintana (coord.), Actas del Cuarto Congreso Internacional de estudios galdosianos (1990). Vol. 2, 57-66.

Gullón, G. (1970): «Tres narradores en busca de un lector». Anales galdosianos, V, 9, 75-80. Disponible en http://www.cervantesvirtual.com/obra/ tres-narradores-en-busca-de-un-lector-o/. 
Gullón, R. (1970): «La última serie». Anales galdosianos, V, 9, 23-35. Disponible en http://www.cervantesvirtual.com/obra/la-historia-como-materianovelable-o/.

Machado, A. ([1938] 1983): «Prólogo» a La Corte de los Milagros de Ramón María del Valle-Inclán. Recopilado en: Julio Rodríguez Puértolas, Gerardo Pérez Herrero (eds.), La Guerra. Escritos: 1936-39. Madrid: Emiliano Escolar Editor, 239-244.

Millares, S. (2020): «Galdós y la mezquindad». Infolibre, 18 de febrero 2020: https://www.infolibre.es/noticias/opinion/plaza_publica/2020/02/18/ galdos_mezquindad_104067_2003.html.

Nietzsche, F. ([1874] 2003): Sobre la utilidad y el perjuicio de la bistoria para la vida. [II intempestiva]. Ed. Germán Cano. Madrid: Biblioteca Nueva.

Pérez Galdós, B. (1897): La sociedad presente como materia novelable. Discurso leido ante la Real Academia de España en su recepción con contestación del Excmo Sr. D. Marcelino Menéndez y Pelayo. Madrid: Viuda e hijos de Tello. Edición facsímil: https://onemorelibrary.com/index.php/es/libros/ literatura/book/literatura-espanola-132/discursos-la-sociedad-presentecomo-materia-novelable-2964.

Pérez Galdós, B. (1870): «Observaciones sobre la novela contemporánea en España». Revista de España, 57. Disponible en https://serescritor. com/wp-content/uploads/2019/02/Observaciones-sobre-la-novelacontempor\% $\mathrm{C}_{3} \%$ A1nea-en-Espa\% $\mathrm{C}_{3} \% \mathrm{~B} 1 \mathrm{a}-$-pdf.pdf.

Pérez Galdós, B. (1897): «La sociedad presente como materia novelable». Discurso de ingreso a la Real Academia de la Lengua. Disponible en https:// www.biblioteca.org.ar/libros/130020.pdf.

Pozuelo Yvancos, J. M., Aradra Sánchez, R. M. (2000). Teoría del canon y literatura española. Madrid: Cátedra.

Reyes, A. ([1943] 1957): «Galdós». En: Obras Completas. México: Fondo de Cultura Económica. Vol. 6, 332-337.

Rodríguez Padrón, J. (2006): «Galdós, ahora». Isidora: revista de estudios galdosianos, 2, 9-18.

Rosell, M. (2008): «Dos creadores heterodoxos, críticos de Galdós: el ensayo de Luis Cernuda y Max Aub». Isidora: revista de estudios galdosianos, 6, 57-68.

Sánchez Cuervo, A., Hermida de Blas, F. (coords.) (2013): Pensamiento exiliado español. El legado filosófico del 39 y de su dimensión iberoamericana. Madrid: Biblioteca Nueva - CSIC. 
Saquillo, J. (2013): «Crucificado por el dolor de España: los exilios de José Bergamín». En: Antolín Sánchez Cuervo, Fernando Hermida de Blas, (coords.), Pensamiento exiliado español. El legado filosófico del 39 y de su dimensión iberoamericana. Madrid: Biblioteca Nueva - CSIC. Posición 2995-3286.

Schopenhauer, A. $\left(2005^{2}\right)$ : El mundo como voluntad y representación. II. Trad. P. López de Santa María. Madrid: Trotta.

Torres Bodet, J. (1969): Tres inventores de la realidad. Sthendhal, Dostoyevski, Pérez Galdós. Madrid: Editorial revista de Occidente.

\section{Galdós in republican exile and his Hispano-American reception}

Key words: Galdosian criticism, José Bergamín, Luis Cernuda, Max Aub, Carlos Blanco Aguinaga

This work explores the Galdosian reading keys offered by three Spanish republican exiles in Mexico - José Bergamín, Max Aub and Luis Cernuda as well as the Spanish-American reception - in the figure of Carlos Blanco Aguinaga - of the generation of writers who succeeded Galdós. In the texts of the three exiled intellectuals, the criticisms of writers of the generations following Galdós are taken apart and the writer's centrality in Spanish literature is restored. He is duly recognised as heir to a literary tradition inaugurated by Cervantes, Quevedo and Lope de Vega, precisely for the same reason that Galdós himself highlighted, drawing on his own work, in his acceptance speech on the occasion of his admission the Royal Spanish Academy in 1897, namely his endeavour to novelize the society that surrounded him.

\section{Galdós v republikanskem pregnanstvu in njegova recepcija v Latinski Ameriki}

Ključne besede: Galdós, José Bergamín, Luis Cernuda, Max Aub, Carlos Blanco Aguinaga

Članek se poglobi v ključe za branje Galdósovih del, ki nam jih ponujajo trije republikanski izgnanci v Mehiki - José Bergamín, Max Aub in Luis Cernuda -, ter prek lika Carlosa Blanca Aguinage v hispanoameriško recepcijo generacije po Galdósu. Besedila treh izgnanih intelektualcev ovržejo kritike pisateljev generacij po Galdósu in kanarskega pisatelja ponovno postavijo v središče 
književnosti v španskem jeziku: imajo ga za dediča literarne genealogije, ki so jo začeli Cervantes, Quevedo in Lope de Vega, prav iz istih razlogov, ki jih je Galdós, izhajajoč iz svojega dela, izpostavil v govoru ob sprejetju v Kraljevo akademijo jezika leta 1897: zaradi njegovega prizadevanja romansirati družbo, ki ga obdaja.

\section{Carmen Domínguez Gutiérrez}

M. Carmen Domínguez Gutiérrez es licenciada en Lingue e Letterature Europee Americane e Postcoloniali en la Universidad Ca' Foscari donde actualmente cursa el doctorado en el programa internacional con Sorbonne Université bajo la dirección de los catedráticos Susanna Regazzoni, Enric Bou y Eduardo Ramos Izquierdo. Su tema de investigación es el exilio hispanoamericano de José Bergamín, miembro de la Generación del 27.

Es, además, licenciada en Historia por la UAM. Ha trabajado en la Real Academia de la Historia y en varias fundaciones culturales españolas como Caja Madrid y Rafael del Pino. Ha traducido obras de historia, arte, estética y filosofía para las editoriales Alianza, Anaya, Biblioteca Nueva o Viella.

Sus estudios se centran en la literatura del exilio republicano español y su relación con la intelectualidad que los cobijó en América Latina (migraciones culturales, exilios políticos, transnacionalidades).

Dirección:

$\begin{aligned} & \text { Ca'Bernardo-Dorsoduro } 3199 \\ & 30123 \text { Venezia } \\ & \text { Italia }\end{aligned}$

Correo electrónico:
Università Ca'Foscari di Venezia

Ca'Bernardo-Dorsoduro 3199

Italia

carmen.dominguez@unive.it 